\title{
RESEARCH
}

Open Access

\section{Association of changes in commute mode with body mass index and visceral adiposity: a longitudinal study}

Keisuke Kuwahara ${ }^{1,2^{*}}$ (D) Hisashi Noma ${ }^{3}$, Tohru Nakagawa ${ }^{4}$, Toru Honda ${ }^{4}$, Shuichiro Yamamoto ${ }^{4}$, Takeshi Hayashi $^{4}$ and Tetsuya Mizoue ${ }^{1}$

\begin{abstract}
Background: Prospective data are sparse for active commuting to work and body weight in Asia. We assessed the association of 5-year changes in commuting mode with body mass index (BMI) and the indicators of abdominal obesity in Japanese working adults.

Methods: In this longitudinal study, we studied 29,758 participants (25,808 men and 3950 women) in Japan aged 30 to 64 years at baseline who underwent further health examination 5 years after the baseline examination. Changes in BMI were calculated from objectively measured body height and weight at baseline and follow-up examination. Visceral and subcutaneous fat areas and waist circumference measured by computed tomography scans were used as indicators for abdominal adiposity. Linear regression was applied to estimate the association of changes in commuting mode with the obesity outcomes.

Results: Within the 5-year study period, adults who maintained inactive commuting gained weight, and compared with this group, adults who switched to inactive commuting had higher weight gain; conversely, adults who switched to active or public transportation commuting and especially those who maintained active or public transportation commuting experienced less weight gain. Subgroup analysis showed similar tendency across the different transitions of leisure-time exercise or occupational physical activity. For example, among adults who maintained no exercise $(n=16,087)$, the adjusted mean (95\% confidence intervals) of the BMI change over 5 years in $\mathrm{kg} / \mathrm{m}^{2}$ were 0.27 (0.24 to 0.30 ) for maintained inactive commuting group (reference), 0.34 (0.30 to 0.38 ) for switching to inactive commuting group $(P=0.046), 0.20$ (0.18 to 0.22$)$ for switching to active commuting or public transportation group $(P=0.001)$, and 0.09 (0.06 to 0.13 ) for maintained active commuting or public transportation group $(P<0.001)$. Maintained inactive commuting tended to be associated with larger gain in abdominal adiposity indicators.

Conclusion: Switching from inactive commuting mode to more physically active commuting mode and maintaining active commuting can promote body weight control among working adults across different levels of occupational or leisure-time physical activity.
\end{abstract}

Keywords: Active commuting, Public transport use, Body weight control, Cohort studies, Asia

\footnotetext{
* Correspondence: kkuwahara@med.teikyo-u.ac.jp

'Department of Epidemiology and Prevention, Center for Clinical Sciences,

National Center for Global Health and Medicine, Tokyo, Japan

${ }^{2}$ Teikyo University Graduate School of Public Health, 2-11-1 Kaga, Itabashi-ku,

Tokyo 173-8605, Japan

Full list of author information is available at the end of the article
}

(C) The Author(s). 2019 Open Access This article is distributed under the terms of the Creative Commons Attribution 4.0 International License (http://creativecommons.org/licenses/by/4.0/), which permits unrestricted use, distribution, and reproduction in any medium, provided you give appropriate credit to the original author(s) and the source, provide a link to the Creative Commons license, and indicate if changes were made. The Creative Commons Public Domain Dedication waiver (http://creativecommons.org/publicdomain/zero/1.0/) applies to the data made available in this article, unless otherwise stated. 


\section{Introduction}

The prevalence of obesity has substantially increased worldwide over 30 years [1], imposing tremendous disease burden [2]. Obesity is particularly prevalent among young to middle-aged adults [3], suggesting that body weight management is critically important in this age group. For many adults, commuting to work is a routine part of daily life. However, car commuting, which is a physically inactive activity, has been the dominant mode of commuting in developed countries $[4,5]$ including Japan [6]. Moreover, the number of private car owners is growing rapidly in developing countries [7], raising numerous health and environmental concerns $[7,8]$. Changing from physically inactive commuting to more active commuting (e.g., walking, cycling, or public transportation use) has been considered as a promising strategy against issues of not only obesity control but also traffic, green gas emission, air pollution, and noise [9-11], as also suggested by the World Health Organization $[12,13]$.

Accumulating evidence suggest that active commuting may help body weight control, whereas prolonged car use may not. However, several points should be further considered. First, most data were derived from cross-sectional studies [14-18], which are limited to infer causality. Second, although some investigated the prospective association of active commuting or car use with body mass index (BMI) [19-24] or obesity [25], two used the exposure measured only at one-time point (at baseline) [24, 25]. Additional data focusing on changes in commuting mode are warranted to establish solid evidence. Third, in five of the seven studies, BMI was estimated based on self-report [19, 21-24], which may not be accurate. Further investigations using objective measurement of BMI are needed to quantify the association between commuting and BMI more precisely. Fourth, these prospective data were obtained in Europe [19-21, 23, 25] or Australia [22, 24], and no data are available in Asian countries, where the average BMI level is lower than that in Western countries [26]. Given that the mean BMI levels and prevalence of obesity have been increasing in Asia [26], evidence to estimate the effects of active commuting to work on BMI is important in Asia to advance health policies for promoting active commuting. Lastly, no prospective data are available regarding the association between active commuting and visceral adiposity, which is a key component of obesity [27].

Herein, we report the 5-year changes in commuting mode to work with simultaneous changes in objectively measured obesity indicators including BMI, waist circumference, and visceral and subcutaneous fat measured via computed tomography (CT) scans among adults with majority of men. We also investigated the commuting-BMI associations according to the leisure-time or occupational physical activity transitions, which may have an impact on the magnitude of BMI change.

\section{Methods}

Study settings

The J-ECOH Study is an ongoing collaborative study to elucidate the risk factors for non-communicable diseases among workers in Japan from more than 10 large-scale companies. We analysed longitudinal data of its subcohort (one major company) where data on primary commuting mode has been collected at the annual health checkup. This company is located in Hitachi city, Ibaraki prefecture, which is a suburban area of East Japan. The type of workplace is a mixture of office and factories. The details of the J-ECOH Study [28] and the present subcohort [29] have been described elsewhere. In Japan, the law requires workers to undergo at least one health examination annually. In this prospective analysis, we included participants who underwent health examinations from April 2006 through March 2011, and the earliest data obtained were considered as baseline (mostly in 2006). Health checkup data obtained 5 year after the baseline examination were collected from April 2011 to March 2016. Prior to the data collection, the conduct of the J-ECOH Study was announced in each participating companies using posters to explain the purpose and procedures of the study. Participants did not provide their verbal or written informed consent to join the study but were allowed to refuse their participation. This consent procedure conforms to the Japanese Ethical Guidelines for Epidemiological Research. The study protocol was approved by the Ethics Committee of the National Center for Global Health and Medicine, Japan.

\section{Participants}

A total of 38,329 participants $(32,486$ men and 5843 women) aged 30 to 64 years at baseline underwent a baseline health examination and a follow-up examination 5 years after baseline measurement. Of these, 478 participants who had a history of cancer or cardiovascular disease at baseline were excluded because these diseases may influence both commuting mode and BMI. Of the remaining 37,851 participants, we further excluded 7102 (18.6\%) who did not have data on commuting mode $(n=4326)$, lifestyle habits (smoking, $n=4266$; alcohol, $n=2783$; sleep, $n=4272$ ), and occupational factors (overtime work, $n=5511$; occupational physical activity, $n=4444$; shift work, $n=5225$; job position, $n=$ 5275) at baseline, leaving 30,749 workers. Some participants met two or more exclusion criteria. Three participants did not have data on body height at baseline, and it was imputed from the following health checkup data. Then, we additionally excluded 991 workers without data on commuting mode after 5-year follow-up, remaining 29,758 participants $(25,808$ men and 3950 women) aged 30 to 64 years (mean [SD]: 43.2 [8.2] years) for the main analysis. Of these, approximately 0.1 to 
$3.5 \%$ of them did not have 5-year follow-up data of covariates (smoking, $n=43$; alcohol, $n=113$; sleep, $n=195$; leisure-time exercise, $n=279$; occupational physical activity, $n=142$; overtime work, $n=323$; shift work, $n=$ 162 ; job position, $n=1040$ ); these missing data of covariates were imputed by using last observation carried forward method. Most of the missing data were replaced by 4-year follow-up data.

\section{Exposure (primary commuting)}

The primary commuting mode to work was selfreported at the annual health examination according to 4 response options of walking, bicycling, train or bus, and car or motorbike. We categorized the 4 types of commuting mode into two groups as (1) inactive commuting (i.e., car or motorbike) and (2) active commuting (i.e., walking or bicycling) or public transportation (train or bus) $[20,30,31]$. We combined active commuting and public transport use as one category because public transport use typically involves in walking [9, 32]. Then, we further reclassified the participants into 4 groups according to the baseline and follow-up commuting mode: (1) maintained inactive commuting, (2) switching from inactive commuting at baseline to active or public transportation mode at 5 years after the baseline examination, (3) switching from active or public transportation mode at baseline to inactive commuting at 5 years after the baseline examination, and (4) maintained active or public transportation mode.

For sensitivity analysis, commuting mode during 1 to 4 years after the baseline period was categorized into the following three categories: persistent inactive commuting, intermittent, and persistent active commuting or public transport use.

\section{Outcome (obesity indicators)}

The body height and weight were measured during annual health examinations, and the BMI of each participant was calculated using the formula $\mathrm{kg} / \mathrm{m}^{2}$. For the main outcome, we obtained the 5-year changes in BMI by subtracting the baseline BMI from the BMI obtained 5 years after baseline.

Visceral and subcutaneous fat areas and waist circumference were measured in a subgroup of the present participants with additional measurements of these variables $(n=4322)$. Single slice imaging was performed at the umbilical level under fasting condition using a Redix Turbo CT scanner (Hitachi Medico, Tokyo, Japan) and visceral fat area, subcutaneous fat area, and waist circumference were estimated by the PC software application fatPointer (Hitachi Medico, Tokyo, Japan) as described elsewhere [33]. Changes from the baseline examination to 5-year follow-up were also calculated for these three obesity indicators as secondary outcomes.

\section{Other variables}

During examination, the lifestyle habits (smoking, alcohol use, sleep duration, and leisure-time exercise), workrelated factors (physical activity at work, overtime work hours, and shift work) and socioeconomic status (job position) of the participants were assessed using a questionnaire. Details of this questionnaire have been explained previously [29]. The metabolic markers for blood pressure, glucose, and lipids were measured following the procedures described elsewhere [34].

\section{Statistical analysis}

We calculated the means (SD) and number (\%) to illustrate baseline characteristics of the participants according to the 5-year changes in commuting mode.

Multivariable linear regression was used to quantify the association of 5-year changes in commuting mode with simultaneous BMI changes. We treated maintained inactive commuting mode as reference. First, we adjusted for baseline variables including age (year, continuous), sex, and BMI $\left(\mathrm{kg} / \mathrm{m}^{2}\right.$, continuous) as model 1 . Then, we adjusted for all factors in model 2, namely, smoking transition (continued no smoking, started smoking, quit smoking, and continued smoking), baseline alcohol use (go [unit for Japanese sake; 1 go of Japanese sake contains about $23 \mathrm{~g}$ of ethanol, which approximates 2 units of alcohol] per day, continuous), 5year changes in alcohol use (go, continuous), baseline sleep duration ( $<5 \mathrm{~h}, 5$ to $<6 \mathrm{~h}, 6$ to $<7 \mathrm{~h}$, and $\geq 7 \mathrm{~h}$ per day), changes in the sleep duration (decrease, no change, or increase), baseline weekly exercise duration during leisure (min, continuous), 5-year changes in the exercise duration (min, continuous), occupational physical activity transition (continued sedentary work, started sedentary work, started physically active work [standing, walking, or physically active], continued physically active work), job position transition (continued low-rank position, promoted, demoted, and continued high-rank position), shift work transition (continued no shift work, started shift work, quit shift work, and continued shift work), and overtime work transition (continued low overtime work hours, increased overtime work hours, decreased overtime work hours, and continued high overtime work hours). The estimated changes in BMI according to commuting mode were calculated from these models. Subgroup analysis was performed for leisure-time exercise transition (persistently no exercise, quit exercise, started exercise, and persistently active) and occupational physical activity (persistently sedentary work, switched to active work, switched to sedentary work, and persistently active work) in model 2 .

We performed the following analyses to confirm the robustness of the results of BMI. First, as about $20 \%$ of participants were excluded due to missing data, we 
performed a sensitivity analysis on the association between commuting and BMI using multiple imputation with chained equations (MICE) for missing data of exposures and covariates at baseline and follow-up. A total of 100 imputed data sets were generated. All analyses were performed on each imputed data set; the 100 estimates were combined into an overall estimate using the rules from Rubin. Second, we conducted an analysis considering the transitions in commuting mode during 1 to 4 years after the baseline. Lastly, we performed an analysis while treating public transport use as an independent category, separated from active commuting.

We repeated the main analysis for other obesity outcomes (visceral fat, subcutaneous fat, and waist circumference) where the baseline obesity outcome was adjusted for in each analysis (e.g., adjustment for baseline visceral fat areas if the outcome is visceral fat change). Two-sided $p$ values of less than 0.05 was considered as statistically significant. All analyses were performed using Stata 14.2 (Stata Corp, College Station, Texas, USA).

\section{Results}

Compared with adults included in the main analysis ( $\mathrm{n}=29,758)$, those excluded due to missing data ( $\mathrm{n}=$ 8093) had a higher proportion of women $(13.3 \%$ vs. $22.5 \%)$ and walked less during commuting $(<20 \mathrm{~min}$ of walking to and from work, $53.5 \%$ vs. $72.6 \%$ ). They were less likely to engage in long overtime work and sedentary work and be in high job position (Additional file 1: Table S1).

Table 1 shows the characteristics of participants at baseline according to the 5-year changes in commuting mode. Adults who maintained inactive commuting tended to engage in physically active work and shift work compared with the other three groups. They were less likely to be in high position and work less overtime hours. Among adults who maintained inactive commuting and those who switched from inactive commuting, approximately $70 \%$ reported $<20$ min of walking to and from work at baseline. Data on blood pressure, glycaemic levels and lipid status, which were available for about 80 to $90 \%$ of participants, were not substantially different across commuting mode. Baseline walking and cycling during leisure and transitions in leisure-time exercise and occupational physical activity were not largely different across changes in commuting mode (Additional file 1: Table S2).

The overall changes in BMI over 5 years were $0.12 \mathrm{~kg} / \mathrm{m}^{2}$ on average. BMI trajectories over 5 years according to transitions in commuting mode are illustrated in Additional file 1: Figure S1. Table 2 shows the multivariable-adjusted BMI changes according to changes in commuting mode. The maintained inactive commuting group showed some weight gain over the 5-year study period (BMI increase of approximately $0.2 \mathrm{~kg} / \mathrm{m}^{2}$ ). Compared with participants who maintained inactive commuting, the participants who switched from active commuting or public transport use to inactive commuting showed higher weight gain. In contrast, the participants who switched from inactive commuting to active commuting or public transport use had lower weight gain. Adults who maintained active commuting or public transportation showed no material weight change. This relationship did not substantially change after adjustment for many potential confounders (model 2); the greatest weight gain was observed in switching to inactive commuting group $\left(0.24 \mathrm{~kg} / \mathrm{m}^{2}, 95 \%\right.$ CI: 0.20 to 0.27$)$, whereas the least gain in maintained active commuting or public transportation group $\left(0.01 \mathrm{~kg} / \mathrm{m}^{2}, 95 \% \mathrm{CI}:-0.01\right.$ to 0.04). A sensitivity analysis using MICE also showed the similar results (Additional file 1: Table S3).

When participants were further divided by commuting mode during 1 to 4 years after baseline, maintaining inactive commuting group tended to persistently use inactive commuting during 1 to 4 years after baseline period, and vice versa (Additional file 1: Table S4). The shape of the association between commuting mode and BMI were generally similar to the main results. Participants who engaged in active commuting or public transport use during 1 to 4 years after baseline tended to show less weight gain compared with other groups (Additional file 1: Table S4).

As illustrated in Table 3, subgroup analysis showed a similar tendency in the association of commuting with BMI in subgroups of exercise transitions or occupational physical activity transition. When public transport use was treated as an independent category, the public transport use is beneficially associated with weight gain as with active commuting (Additional file 1: Table S5) even when divided by transitions in exercise or occupational physical activity (Additional file 1: Tables S6 to S7).

The associations to visceral adiposity (waist circumference, visceral fat areas, and subcutaneous fat areas) among 4322 participants who received visceral adiposity CT scans (maintained inactive group, $n=2129$; switching from active or public transportation commuting to inactive group, $n=328$; switching from inactive to active or public transportation commuting group, $n=322$; maintained active or public transportation commuting group, $n=1532$ ) are shown in Table 4 . The relationships between commuting mode and the outcomes were less clear than those for BMI. However, maintained inactive commuting tended to show larger gain in these abdominal indicators compared with other commuting patterns (Table 4).

\section{Discussion}

In this 5-year observation of approximately 30,000 Japanese workers, maintaining inactive commuting mode was associated with weight gain; compared with this group, switching 
Table 1 Baseline characteristics of the participants according to changes in commuting mode over 5 years $(n=29,758)$

\begin{tabular}{|c|c|c|c|c|}
\hline Baseline variables & $\begin{array}{l}\text { Maintained } \\
\text { inactive commute } \\
(n=14,704)\end{array}$ & $\begin{array}{l}\text { Switched from active or public } \\
\text { transportation to inactive commute }(n=2485)\end{array}$ & $\begin{array}{l}\text { Switched from inactive to active or } \\
\text { public transportation commute } \\
(n=2359)\end{array}$ & $\begin{array}{l}\text { Maintained active or } \\
\text { public transportation } \\
(n=10,210)\end{array}$ \\
\hline Age, years & $43.1 \pm 8.1$ & $42.0 \pm 8.1$ & $42.1 \pm 7.9$ & $43.8 \pm 8.2$ \\
\hline Men, n (\%) & $12,405(84.4)$ & 2147 (86.4) & $2023(85.8)$ & $9233(90.4)$ \\
\hline $\begin{array}{l}\text { Body mass index, } \\
\mathrm{kg} / \mathrm{m}^{2}\end{array}$ & $23.5 \pm 3.5$ & $23.6 \pm 3.5$ & $23.6 \pm 3.5$ & $23.6 \pm 3.3$ \\
\hline Body weight, kg & $67.0 \pm 12.0$ & $67.9 \pm 12.1$ & $67.7 \pm 12.2$ & $68.0 \pm 11.3$ \\
\hline $\begin{array}{l}\text { Visceral fat areas, } \\
\mathrm{cm}^{2 \mathrm{~b}}\end{array}$ & $119.0 \pm 50.7$ & $122.0 \pm 48.2$ & $130.6 \pm 53.6$ & $119.8 \pm 51.3$ \\
\hline $\begin{array}{l}\text { Subcutaneous fat } \\
\text { areas, } \mathrm{cm}^{2} \mathrm{~b}\end{array}$ & $141.2 \pm 61.2$ & $146.2 \pm 62.0$ & $145.8 \pm 59.0$ & $137.8 \pm 58.1$ \\
\hline $\begin{array}{l}\text { Waist } \\
\text { circumference, } \\
\mathrm{cm}^{\mathrm{b}}\end{array}$ & $86.4 \pm 8.6$ & $87.0 \pm 8.4$ & $87.8 \pm 8.5$ & $86.3 \pm 8.3$ \\
\hline $\begin{array}{l}\text { Systolic blood } \\
\text { pressure, } \mathrm{mm} \mathrm{Hg}\end{array}$ & $121.7 \pm 14.1$ & $121.0 \pm 14.2$ & $121.3 \pm 14.0$ & $122.1 \pm 14.2$ \\
\hline $\begin{array}{l}\text { Diastolic blood } \\
\text { pressure, } \mathrm{mm} \mathrm{Hg}\end{array}$ & $75.9 \pm 10.1$ & $75.5 \pm 10.3$ & $75.9 \pm 9.9$ & $76.5 \pm 10.1$ \\
\hline $\begin{array}{l}\text { Treatment for } \\
\text { hypertension, n } \\
\text { (\%) }\end{array}$ & $1021(6.9)$ & $163(6.6)$ & $135(5.7)$ & 708 (6.9) \\
\hline $\begin{array}{l}\text { Fasting } \\
\text { triglyceride, mg/ } \\
d^{c}{ }^{c}\end{array}$ & $125.6 \pm 89.3$ & $131.8 \pm 93.9$ & $131.3 \pm 97.0$ & $130.1 \pm 95.3$ \\
\hline $\begin{array}{l}\mathrm{HDL} \text {-cholesterol, } \\
\mathrm{mg} / \mathrm{dL}^{\mathrm{c}}\end{array}$ & $55.6 \pm 14.1$ & $55.5 \pm 14.2$ & $55.3 \pm 13.9$ & $55.9 \pm 14.0$ \\
\hline $\begin{array}{l}\text { LDL-cholesterol, } \\
\mathrm{mg} / \mathrm{dL}^{\mathrm{c}}\end{array}$ & $118.7 \pm 30.6$ & $118.1 \pm 30.0$ & $118.5 \pm 30.6$ & $119.3 \pm 29.4$ \\
\hline $\begin{array}{l}\text { Treatment for } \\
\text { dyslipidemia, n (\%) }\end{array}$ & $654(4.5)$ & $96(3.9)$ & $108(4.6)$ & $412(4.0)$ \\
\hline $\begin{array}{l}\text { Fasting plasma } \\
\text { glucose, } \mathrm{mg} / \mathrm{dL}^{\mathrm{c}}\end{array}$ & $100.5 \pm 18.7$ & $100.5 \pm 19.8$ & $99.5 \pm 16.5$ & $101.6 \pm 19.1$ \\
\hline $\mathrm{HbA} 1 \mathrm{c}, \%^{\mathrm{c}}$ & $5.7 \pm 0.7$ & $5.7 \pm 0.7$ & $5.6 \pm 0.7$ & $5.7 \pm 0.7$ \\
\hline $\begin{array}{l}\text { Treatment for } \\
\text { diabetes, } \mathrm{n}(\%)\end{array}$ & 405 (2.8) & $75(3.0)$ & $50(2.1)$ & $288(2.8)$ \\
\hline $\begin{array}{l}\text { Current smokers, } \mathrm{n} \\
(\%)\end{array}$ & 7021 (47.7) & 3663 (35.9) & $1058(42.6)$ & 1029 (43.6) \\
\hline $\begin{array}{l}\text { Ethanol } \\
\text { consumption of } \\
\geq 46 \text { g per day, } \mathrm{n} \\
\text { (\%) }\end{array}$ & $1291(8.8)$ & $231(9.3)$ & $214(9.1)$ & 977 (9.6) \\
\hline $\begin{array}{l}\text { Sleep duration of } \\
<6 \mathrm{~h} / \text { day, } \mathrm{n}(\%)\end{array}$ & 7504 (51.1) & $1313(52.9)$ & $1260(53.4)$ & 5393 (52.8) \\
\hline $\begin{array}{l}\text { Leisure-time } \\
\text { exercise in } \mathrm{min} / \\
\text { week }\end{array}$ & $56.1 \pm 147.6$ & $47.1 \pm 107.1$ & $56.8 \pm 139.1$ & $48.1 \pm 120.6$ \\
\hline $\begin{array}{l}\text { No leisure-time ex- } \\
\text { ercise, } n(\%)\end{array}$ & 9567 (65.1) & $1663(66.9)$ & $1513(64.1)$ & $6838(67.0)$ \\
\hline $\begin{array}{l}\text { Sedentary work, n } \\
(\%)\end{array}$ & 7810 (53.1) & $1660(66.8)$ & $1588(67.3)$ & 7486 (73.3) \\
\hline Shift work, n (\%) & 3450 (23.5) & $372(15.0)$ & $362(15.4)$ & $976(9.6)$ \\
\hline $\begin{array}{l}\text { Not in high job } \\
\text { position, } \mathrm{n}(\%)\end{array}$ & $12,745(86.7)$ & 2004 (80.6) & 1845 (78.2) & 7532 (73.8) \\
\hline Overtime work & 4987 (33.9) & 959 (38.6) & 958 (40.6) & 3973 (38.9) \\
\hline
\end{tabular}


Table 1 Baseline characteristics of the participants according to changes in commuting mode over 5 years $(n=29,758)($ Continued)

\begin{tabular}{|c|c|c|c|c|}
\hline Baseline variables & $\begin{array}{l}\text { Maintained } \\
\text { inactive commute } \\
(n=14,704)\end{array}$ & $\begin{array}{l}\text { Switched from active or public } \\
\text { transportation to inactive commute }(n=2485)\end{array}$ & $\begin{array}{l}\text { Switched from inactive to active or } \\
\text { public transportation commute } \\
(n=2359)\end{array}$ & $\begin{array}{l}\text { r Maintained active or } \\
\text { public transportation } \\
(n=10,210)\end{array}$ \\
\hline
\end{tabular}

$\geq 45$ h/month, $\mathrm{n}$

$(\%)$

Primary commute mode, $\mathrm{n}(\%)$

\begin{tabular}{|c|c|c|c|c|}
\hline Walking & $0(0)$ & $659(26.5)$ & $0(0)$ & $3017(29.6$ \\
\hline Cycling & $0(0)$ & $930(37.4)$ & $0(0)$ & 1980 (19.4 \\
\hline $\begin{array}{l}\text { Bus/train (public } \\
\text { transportation) }\end{array}$ & $0(0)$ & $896(36.1)$ & $0(0)$ & $5213(51$. \\
\hline Car/motorbike & $14,704(100)$ & $0(0)$ & $2359(100)$ & $0(0)$ \\
\hline
\end{tabular}

Walking to and from work

\begin{tabular}{|c|c|c|c|c|}
\hline$<20$ min, n (\%) & $10,730(73.0)$ & 1029 (41.4) & 1669 (70.8) & $2503(24.5)$ \\
\hline $\begin{array}{l}20 \text { to }<40 \mathrm{~min}, \mathrm{n} \\
(\%)\end{array}$ & $3708(25.2)$ & 969 (39.0) & $632(26.8)$ & 4277 (41.9) \\
\hline$\geq 40$ min, n (\%) & 266 (1.8) & 487 (19.6) & $58(2.5)$ & 3430 (33.6) \\
\hline
\end{tabular}

HbA1c hemoglobin A1c, HDL high-density lipoprotein, LDL low-density lipoprotein

Data are shown as mean \pm SD for continuous variables or number (\%) for categorical variables

${ }^{a}$ Inactive commuting mode was defined as commuting by car or motorbike

${ }^{b}$ Visceral and subcutaneous fat areas were measured using CT scans among 2129 participants for maintaining inactive commute group, 328 for switching to inactive mode group, 322 for switching to active or public transportation use group, and 1543 for maintaining active or transportation mode group. Meanwhile, the corresponding numbers for CT-scan measured waist circumference were 1672, 256, 266, and 1272, respectively

'Data on fasting triglyceride were available among 12,373 participants for maintaining inactive commuting, 2055 for switching to inactive commuting, 1935 for switching to active commuting, and 8753 for maintaining active commuting. For fating or non-fasting HDL, the corresponding numbers were $13,215,2163,2052$, and 9073; for fasting or non-fasting LDL, 13,118, 2147, 2027, and 9003; for fasting glucose, 12,354, 2050, 1931, and 8742; for HbA1c, 13,195, 2158, 2050, and 9058, respectively

from active or public transportation commuting to inactive commuting were associated with larger weight gain, and vice versa. Further sensitivity analyses supported the main findings. To the best of our knowledge, this is the first study to estimate the impact of changes in commuting mode to work on body weight and visceral adiposity changes in Asia.

The present analysis showed that adults who maintained inactive commuting gained weight over 5 years $(0.19 \mathrm{~kg} /$ $\mathrm{m}^{2}$ ), and adults who switched from active or public transportation commuting at baseline to inactive commuting at follow-up had greater weight gain $\left(0.24 \mathrm{~kg} / \mathrm{m}^{2}\right)$ than those who maintained inactive commuting. By contrast, those who switched to and those who maintained active commuting or public transportation showed less weight gain than those who maintaining inactive commuting $\left(0.10 \mathrm{~kg} / \mathrm{m}^{2}\right.$ and $0.01 \mathrm{~kg} / \mathrm{m}^{2}$, respectively). Prospective studies [19-21, 23] have also shown similar trends of changes in BMI according to changes in commuting mode, although categories of the changes in exposure is somewhat heterogeneous. Additionally, an Australian study reported that persistent active commuting was associated with a lower BMI [22]. A recent systematic review also showed that public transport use is associated

Table 2 Changes in body mass index $\left(\mathrm{kg} / \mathrm{m}^{2}\right)$ over 5 years as classified according to commuting mode transition $(n=29,758)$

\begin{tabular}{|c|c|c|c|c|}
\hline & \multicolumn{4}{|c|}{ Commuting mode transition over 5 years } \\
\hline & $\begin{array}{l}\text { Maintained } \\
\text { inactive }\end{array}$ & $\begin{array}{l}\text { Switching to } \\
\text { inactive }\end{array}$ & $\begin{array}{l}\text { Switching to active or } \\
\text { public transportation }\end{array}$ & $\begin{array}{l}\text { Maintained active or } \\
\text { public transportation }\end{array}$ \\
\hline \multirow[t]{2}{*}{ Crude model } & $0.18(0.16,0.20)$ & $0.27(0.21,0.33)$ & $0.07(0.01,0.13)$ & $0.02(-0.01,0.05)$ \\
\hline & Reference & $P=0.005$ & $P=0.001$ & $P<0.001$ \\
\hline \multirow[t]{2}{*}{ Multivariable model $1^{\text {a }}$} & $0.18(0.16,0.20)$ & $0.26(0.23,0.29)$ & $0.11(0.09,0.13)$ & $0.01(-0.01,0.04)$ \\
\hline & Reference & $P=0.006$ & $P<0.001$ & $P<0.001$ \\
\hline \multirow[t]{2}{*}{ Multivariable model $2^{b}$} & $0.19(0.17,0.21)$ & $0.24(0.20,0.27)$ & $0.10(0.09,0.12)$ & $0.01(-0.01,0.04)$ \\
\hline & Reference & $P<0.001$ & $P=0.001$ & $P<0.001$ \\
\hline
\end{tabular}

Data are shown as estimated mean with $95 \%$ confidence intervals. Ref, Reference

${ }^{a}$ Model 1: Baseline variables of age, sex, and body mass index were adjusted

${ }^{b}$ Model 2: Further adjusted for smoking transition, baseline alcohol consumption, 5-year changes in alcohol consumption, baseline sleep duration, changes in the sleep duration, baseline weekly exercise duration during leisure, 5-year changes in the exercise duration, occupational physical activity transition, job position transition, shift work transition, and overtime work transition 
Table 3 Changes in commuting mode and BMI $\left(\mathrm{kg} / \mathrm{m}^{2}\right)$ as classified according to exercise transition or occupational physical activity transition

\begin{tabular}{|c|c|c|c|c|}
\hline & \multicolumn{4}{|c|}{ Commuting mode transition over 5 years } \\
\hline & Maintained inactive & $\begin{array}{l}\text { Switching to } \\
\text { inactive }\end{array}$ & $\begin{array}{l}\text { Switching to active or } \\
\text { public transportation }\end{array}$ & $\begin{array}{l}\text { Maintained active or } \\
\text { public transportation }\end{array}$ \\
\hline \multicolumn{5}{|l|}{ Leisure-time exercise } \\
\hline Maintained no exercise & $0.27(0.24,0.30)$ & $0.34(0.30,0.38)$ & $0.20(0.18,0.22)$ & $0.09(0.06,0.13)$ \\
\hline$n=16,087$ & Reference & $P<0.001$ & $P=0.046$ & $P<0.001$ \\
\hline Quit exercise & $0.34(0.28,0.40)$ & $0.41(0.31,0.50)$ & $0.25(0.20,0.30)$ & $0.18(0.10,0.26)$ \\
\hline$n=6619$ & Reference & $P=0.34$ & $P=0.002$ & $P=0.071$ \\
\hline Started exercise & $-0.13(-0.20,-0.07)$ & $-0.12(-0.23,-0.02)$ & $-0.28(-0.34,-0.22)$ & $-0.38(-0.46,-0.29)$ \\
\hline$n=3494$ & Reference & $P=0.072$ & $P=0.38$ & $P=0.27$ \\
\hline Maintained exercise & $0.06(0.02,0.10)$ & $0.11(0.04,0.17)$ & $0.01(-0.03,0.04)$ & $-0.07(-0.12,-0.02)$ \\
\hline$n=6619$ & Reference & $P=0.73$ & $P=0.19$ & $P<0.001$ \\
\hline \multicolumn{5}{|l|}{ Occupational activity } \\
\hline Maintained sedentary & $0.14(0.11,0.16)$ & $0.21(0.16,0.25)$ & $0.06(0.03,0.08)$ & $-0.03(-0.06,0.00)$ \\
\hline$n=16,985$ & Reference & $P=0.001$ & $P=0.006$ & $P<0.001$ \\
\hline Changed to sedentary & $0.43(0.36,0.51)$ & $0.45(0.33,0.57)$ & $0.41(0.34,0.48)$ & $0.35(0.24,0.46)$ \\
\hline$n=1937$ & Reference & $P=0.99$ & $P=0.28$ & $P=0.77$ \\
\hline Changed to active & $0.00(-0.08,0.08)$ & $0.01(-0.12,0.14)$ & $0.03(-0.05,0.12)$ & $-0.09(-0.21,0.03)$ \\
\hline$n=1559$ & Reference & $P=0.70$ & $P=0.50$ & $P=0.50$ \\
\hline Maintained active & $0.23(0.20,0.26)$ & $0.29(0.24,0.35)$ & $0.17(0.14,0.20)$ & $0.08(0.02,0.13)$ \\
\hline$n=9277$ & Reference & $P=0.005$ & $P=0.038$ & $P=0.047$ \\
\hline
\end{tabular}

Data are shown as estimated mean and $95 \%$ confidence intervals. Data were adjusted for factors in model 2

Table 4 Changes in indicators of abdominal obesity as classified according to commuting mode transition $(n=4322)$

\begin{tabular}{|c|c|c|c|c|c|c|}
\hline & Crude model & $P$ values & Multivariable model $1^{\text {a }}$ & $P$ values & Multivariable model $2^{b}$ & $P$ values \\
\hline \multicolumn{7}{|l|}{ Waist circumference (cm) } \\
\hline Maintained inactive & $0.7(0.4,1.0)$ & Reference & $0.9(0.6,1.1)$ & Reference & $0.9(0.6,1.1)$ & Reference \\
\hline Switching to inactive & $1.2(0.6,1.9)$ & 0.20 & $0.9(0.5,1.2)$ & 0.15 & $0.8(0.4,1.2)$ & 0.10 \\
\hline Switching to active or public transportation & $-0.4(-1.1,0.4)$ & 0.007 & $0.6(0.4,0.8)$ & 0.052 & $0.5(0.3,0.7)$ & 0.17 \\
\hline Maintained active or transportation & $0.7(0.4,1.1)$ & 0.98 & $0.7(0.4,1.0)$ & 0.85 & $0.7(0.4,1.0)$ & 0.27 \\
\hline \multicolumn{7}{|l|}{ Visceral fat areas $\left(\mathrm{cm}^{2}\right)$} \\
\hline Maintained inactive & $5.3(3.7,6.9)$ & Reference & $5.4(4.1,6.6)$ & Reference & $5.6(4.3,6.9)$ & Reference \\
\hline Switching to inactive & $6.4(2.4,10.3)$ & 0.58 & $5.2(3.1,7.3)$ & 0.63 & $4.4(2.3,6.5)$ & 0.20 \\
\hline Switching to active or public transportation & $-0.8(-5.4,3.9)$ & 0.007 & $2.2(1.1,3.4)$ & 0.11 & $1.5(0.3,2.7)$ & 0.25 \\
\hline Maintained active or public transportation & $4.6(2.8,6.4)$ & 0.64 & $4.2(2.5,5.9)$ & 0.42 & $4.2(2.5,5.9)$ & 0.59 \\
\hline \multicolumn{7}{|l|}{ Subcutaneous fat areas $\left(\mathrm{cm}^{2}\right)$} \\
\hline Maintained inactive & $5.1(3.7,6.5)$ & Reference & $5.0(3.9,6.2)$ & Reference & $5.4(4.2,6.5)$ & Reference \\
\hline Switching to inactive & $5.7(2.0,9.5)$ & 0.73 & $5.5(3.6,7.3)$ & 0.55 & $4.2(2.4,6.0)$ & 0.19 \\
\hline Switching to active or public transportation & $2.0(-1.5,5.5)$ & 0.11 & $3.2(1.8,4.7)$ & 0.16 & $3.0(2.0,4.0)$ & 0.51 \\
\hline Maintained active or public transportation & $3.5(1.9,5.0)$ & 0.13 & $3.7(2.8,4.7)$ & 0.13 & $3.2(1.7,4.7)$ & 0.80 \\
\hline
\end{tabular}

Data are shown as estimated mean with $95 \%$ confidence intervals of changes in obesity outcome. Maintained inactive group, $n=2129$; switching from active or public transportation commuting to inactive group, $n=328$; switching from inactive to active or public transportation commuting group, $n=322 ;$ maintained active or public transportation commuting group, $n=1532$

${ }^{a}$ Model 1: Adjusted for age and sex at baseline. In addition, baseline variables of each outcome, treated as continuous data, were adjusted for (e.g., baseline waist circumference when outcome is changes in waist circumference)

${ }^{\mathrm{b}}$ Model 2: Further adjusted for other variables 
with a lower BMI [35]. Collectively, these findings indicate that switching from inactive commuting mode to more physically active commuting and maintaining active commuting or public transport use over time may be beneficially associated with body weight among working adults.

In the present data, adults who switched to inactive commuting tended to show greater weight gain compared with other groups. A UK study also reported a similar finding [21]. The reason of the greater gain is unclear. However, in theory, reductions in energy expenditure may lead to difficulty in maintain energy balance [36], resulting in weight gain [36]. As the related data are sparse, additional studies on this issue, as well as studies which can elucidate the underlying mechanisms are warranted.

The extent of BMI change in the present study was smaller than those in the comparable longitudinal studies [19-21, 23]. This is may be due to that average BMI level in the present study is lower than those in the previous Western studies [19-21, 23] $\left(23.5 \mathrm{~kg} / \mathrm{m}^{2}\right.$ vs. approximately 24 to $27 \mathrm{~kg} / \mathrm{m}^{2}$ ); the extent of weight change in Asians may be smaller than Caucasians. Another reason of smaller changes in BMI in the present study might be partly explained by the differences in the assessment of BMI. The present study used objectively measured body height and weight, whereas most of the previous studies used self-report [19, 21, 23]. Nonetheless, Asians tend to develop diabetes even with a small weight gain [37] and accumulating evidence suggest that obesity even without metabolic abnormality may increase risk of all-cause mortality and cardiovascular disease [38]. Although weight change associated with commuting mode was small, the present results would provide important viewpoint to prevent or delay the onset of non-communicable diseases in Asians. Besides obesity, promotion of active commuting and public transport use would help solve health-related problems including traffic-related air pollution and noise [11]. Given the limited available data, further large studies from Asia are needed to establish the solid evidence on commuting and BMI in Asia.

Our novel finding is that the beneficial association of active or public transportation commuting with BMI was observed across different transitions of leisure-time exercise and occupational physical activity, while both leisure-time exercise and occupational physical activity were inversely associated with BMI over time. Similarly with the present findings, observational studies have shown that exercise was associated with weight reduction [39]. Although prospective data are sparse, increase in occupational physical activity over time was inversely associated with BMI [20, 40]. Importantly, the present data showed that maintaining or switching to active commuting or public transport use are respectively associated with less weight gain even among those who did not engage in exercise and those who engaged in sedentary at work (Additional file 1: S6 and S7). Both active commuting and public transport use may be a good source of physical activity among adults who are inactive during leisure or at workplace.

In the present analysis for abdominal obesity (i.e., waist circumference, visceral fat areas, and subcutaneous fat areas) measured by $\mathrm{CT}$ scans, maintaining inactive commuting tended to show larger gain in these parameters than other commuting patterns. However, these changes did not reach significance and were somewhat different from those of BMI. The non-significant and less clear changes may be due to the small sample size with abdominal CT measurements in our data set when participants were divided according to commuting mode transition (especially for those who changed the commuting mode, $n=320$ to 330 ). Nonetheless, recent randomised controlled trials showed that active commuting by cycling reduced body fat mass compared with no intervention [41, 42]. Although we are not aware of any observational study on the prospective association of active commuting to work with visceral adiposity, one cross-sectional study in the UK [30] reported that active commuters tended to show lower visceral adipose tissue mass compared with those commuting only by car. By contrast, another cross-sectional study in Thailand [43] reported an opposite finding and found higher odds of having central obesity in adults who were actively commuting; their finding may be ascribed to reverse causality. As available longitudinal data are still limited, further large-scale studies are needed to elucidate the association of active commuting and public transport use with abdominal obesity.

The present data showed that leisure-time exercise and occupational physical activity were not largely different across different transitions in commuting mode; only exception was that adults maintaining inactive commuting were less likely to engage in sedentary work. These results are somewhat different from recent findings from a cross-sectional study [44] showing that walking during commuting was positively associated with cycling during leisure and negatively associated with leisure-time physical activity among French adults. Although the causalrelationship among domain-specific physical activities is unclear, this kind of information would help detect high risk population of physical inactivity, which should be a target for physical activity intervention.

It would be important to discuss implication of the present findings for physical activity promotion. In Japan, Ministry of Land, Infrastructure, Transport and Tourism has engaged in policies on promoting active commuting including walking and cycling and switching 
from car commuting to public transport use [45]. In addition, Japan Sport Agency, which is under Ministry of Education, Culture, Sports, Science and Technology, recently launched a project for promoting walking during commuting or at workplace especially among working adults [46]. However, supporting evidence for these actions, especially for switching to public transport use, has been lacking in relation to health. Therefore, the present data would support high level policy makers and other stakeholders (e.g., local governments, transport agencies, health professionals) to advance such actions from the viewpoint of health promotion. As summarized by Sallis et al. [47] and declared by Japanese Association of Exercise Epidemiology [48] recently, providing scientific knowledge including the present findings to such stakeholders would be important to ensure evidencebased policy making in Japan.

The strengths of this study include its longitudinal design that provides more convincing evidence than crosssectional design. Further, this is the largest study on this topic to date, enabling us to detect an association with a greater statistical power. We used objectively measured BMI and visceral adiposity.

The limitations of this study also need to be clarified. First, we assessed the primary commuting mode via selfreports. Therefore, random misclassifications might have diluted the results. Second, the present questionnaire for commuting mode was not designed to estimate the precise volume or intensity of physical activity and sedentary behaviour during commuting, which may have an impact on body weight and composition [49-52]. Although we are not aware of any Asian studies showing time spent in walking during commuting by commuting mode, our findings are similar to those from a recent UK study [53] reporting that approximately 20 to $30 \mathrm{~min}$ of walking per day accumulated during public transport. It is possible that public transport users with shorter time spent in walking and/or cycling to public transport access points may benefit less than those with longer time [30]. In addition, we found that, among participants who persistently used public transport as main commuting mode, longer time spent in walking to and from work was related to less weight gain (Additional file 1: Table S8). Third, unmeasured and/or residual confounders may have affected the results, although we adjusted for many covariates. Fourth, we do not have data on the reason for the changes in commuting mode. Some participants might have switched to active commuting to control body weight or health condition and such people may tend to adhere to multiple healthy lifestyles. However, baseline levels of BMI and other metabolic markers including blood pressures, glucose, and lipids were not substantially different across the various transitions of commuting mode and we adjusted for multiple lifestyle factors. Therefore, such possibility might be low. Fifth, approximately $20 \%$ of participants were excluded from the main analysis due to missing data, and some characteristics were slightly different between those included and excluded. However, our sensitivity analysis using MICE showed similar results with those from the primary analysis. Sixth, timing of switching in commuting mode would affect the results as the exposure period is different. However, we did not further examine this issue in detail as sample size is insufficient when participants were further divided by the timing of the change, although we roughly considered the transitions in commuting mode during 1 to 4 years after baseline in an additional analysis. Future studies using different definition of switching (e.g., participant reported car use in the first year, but switched to walking in the second year, then examine the change in the outcomes between the first and third year) are needed. Seventh, we examined the association of 5-year changes in exposure with simultaneous changes in outcomes. Another analytical approach including difference-indifference analysis with considering non-linear association [54, 55] would help understand the longitudinal relationship between commuting mode and health outcomes. Lastly, the data were obtained from workers in a large-scale company in Japan and the majority were men. Therefore, caution should be exercised when generalising the present findings to workers in small to medium-sized enterprises and women.

In conclusion, we found that switching from inactive commuting to active or public transportation commuting was associated with less BMI increase. Meanwhile, switching from active commuting or public transport use to inactive commuting was associated with higher increase in BMI among Japanese men and women. This relationship was mostly unchanged across different transitions of leisure-time exercise or occupational physical activity. The promotion of active commuting and/or public transportation use at the population level by various stakeholders, including policy makers, local government officials, and companies, would help to end the global obesity epidemic.

\section{Supplementary information}

Supplementary information accompanies this paper at https://doi.org/10. 1186/s12966-019-0870-x

\footnotetext{
Additional file 1: Table S1. Characteristics of participants included and excluded from the main analysis. Table S2. Association of changes in commuting mode with baseline exercise and transitions in leisure-time exercise or occupational physical activity. Table S3. A sensitivity analysis on the changes in commuting mode and BMI with multiple imputation using chained equations ( $n=37,847$ ). Table S4. A sensitivity analysis for BMI with consideration of transitions in commuting mode during 1 to 4 years after baseline $(n=24,686)$. Table $\mathbf{S 5}$. Associations of active commuting, public transport use, and inactive commuting with BMI. Table S6. Associations
} 
of active commuting, public transport use, and inactive commuting with BMI by leisure-time exercise transition. Table S7. Associations of active commuting, public transport use, and inactive commuting with BMl by occupational physical activity transition. Table S8. Changes in BMI over 5 years according to the transitions in time spent in walking to and from work among workers who persistently used public transport as main commuting mode Figure S1. Trajectories of non-adjusted average body mass index according to the changes in commuting mode.

\section{Abbreviations}

BMI: Body mass index; Cl: Confidence interval; CT: Computed tomography; JECOH: Japan Epidemiology Collaboration on Occupational Health; MICE: Multiple imputation with chained equations

\section{Acknowledgements}

The authors thank Toshiteru Ohkubo (Director of Industrial Health Foundation) for scientific advice on the J-ECOH Study, Maki Konishi (National Center for Global Health and Medicine) for data management, and Rika Osawa (National Center for Global Health and Medicine) for administrative support

\section{Authors' contributions}

KK drafted the concept and design, performed the analysis, and drafted the manuscript. HN helped the advanced statistical analysis. TN, TH, SY, and TH provided databases for the present study and implications of the findings. TM commented on and edited the drafts. KK produced the final manuscript. All authors approved the final manuscript.

\section{Funding}

This work was supported by grants from the Japan Society for the Promotion of Science (25871166, 16 K21379, and 19 K10671), a fund from National Center for Global Health and Medicine (28-Shi-1206), the Industrial Health Foundation, and the Industrial Disease Clinical Research Grants (170301-01) from the Ministry of Health, Labour and Welfare, Japan.

\section{Availability of data and materials}

The datasets generated and/or analysed during the current study are not publicly available due ethical restrictions and participant confidentiality concerns, but de-identified data are available from Dr. Mizoue (Department of Epidemiology and Prevention, Center for Clinical Sciences, National Center for Global Health and Medicine, Tokyo, Japan) to qualified researchers on reasonable request.

\section{Ethics approval and consent to participate}

The study protocol, including the consent procedure, was approved by the Ethics Committee of the National Center for Global Health and Medicine, Japan. Prior to the data collection, the conduct of the J-ECOH Study was announced in each participating companies using posters to explain the purpose and procedures of the study. Participants did not provide their verbal or written informed consent to join the study but were allowed to refuse their participation. This procedure conforms to the Japanese Ethical Guidelines for Epidemiological Research.

\section{Consent for publication}

Not applicable.

\section{Competing interests}

The authors declare no conflict of interest. T.N., S.Y., T.H., and T.H. are occupational physicians in the participating company.

\section{Author details}

'Department of Epidemiology and Prevention, Center for Clinical Sciences, National Center for Global Health and Medicine, Tokyo, Japan. ${ }^{2}$ Teikyo University Graduate School of Public Health, 2-11-1 Kaga, Itabashi-ku, Tokyo 173-8605, Japan. ${ }^{3}$ The Institute of Statistical Mathematics, Tokyo, Japan. ${ }^{4}$ Hitachi Health Care Center, Hitachi, Ltd, Ibaraki, Japan.
Received: 5 July 2019 Accepted: 22 October 2019

Published online: 06 November 2019

\section{References}

1. Ng M, Fleming T, Robinson M, Thomson B, Graetz N, Margono C, et al. Global, regional, and national prevalence of overweight and obesity in children and adults during 1980-2013: a systematic analysis for the global burden of disease study 2013. Lancet. 2014;384(9945):766-81.

2. GBD 2015 Obesity Collaborators, Afshin A, Forouzanfar MH, Reitsma MB, Sur P, Estep K, Lee A, et al. Health Effects of Overweight and Obesity in 195 Countries over 25 Years. N Engl J Med. 2017;377(1):13-27.

3. Ogden $\mathrm{CL}$, Carroll MD, Kit BK, Flegal KM. Prevalence of childhood and adult obesity in the United States, 2011-2012. JAMA. 2014;311(8):806-14.

4. Goodman A. Walking, cycling and driving to work in the English and welsh 2011 census: trends, socio-economic patterning and relevance to travel behaviour in general. PLoS One. 2013;8(8):e71790.

5. McKenzie B, Rapino M. Commuting in the U.S.: 2009 American community survey reports. Washington DC: U.S. Census Bereau; 2011.

6. Statistics Bureau, Ministry of Internal Affairs and Communications, Japan. The 2010 Population census. Ministry of Internal Affiars nad Communications, Japan, Tokyo, 2012

7. Pucher J, Peng Z, Mittal N, Zhu Y, Korattyswaroopam N. Urban transport trends and policies in China and India: impacts of rapid economic growth. Transp Rev. 2007:27(4):397-410.

8. Gong P, Liang S, Carlton EJ, Jiang Q, Wu J, Wang L, et al. Urbanisation and health in China. Lancet. 2012;379(9818):843-52.

9. Sallis JF, Frank LD, Saelens BE, Kraft MK. Active transportation and physical activity: opportunities for collaboration on transportation and public health research. Transp Res Part A Policy Pract. 2004;38(4):249-68.

10. Braun LM, Rodriguez DA, Song Y, Meyer KA, Lewis CE, Reis JP, et al. Changes in walking, body mass index, and cardiometabolic risk factors following residential relocation: longitudinal results from the CARDIA study. J Transp Health. 2016:3(4):426-39.

11. Giles-Corti B, Vernez-Moudon A, Reis R, Turrell G, Dannenberg AL, Badland $H$, et al. City planning and population health: a global challenge. Lancet. 2016;388(10062):2912-24.

12. World Health Organization. Global recommendations on physical activity for health. Geneva, 2010.

13. World Health Organization: Global action plan on physical activity 20182030: more active people for a healthier world. Geneva, 2018

14. Laverty AA, Webb E, Vamos EP, Millett C. Associations of increases in public transport use with physical activity and adiposity in older adults. Int J Behav Nutr Phys Act. 2018;15(1):31.

15. Flint E, Cummins S, Sacker A. Associations between active commuting, body fat, and body mass index: population based, cross sectional study in the United Kingdom. BMJ. 2014;349:94887.

16. Millett C, Agrawal S, Sullivan R, Vaz M, Kurpad A, Bharathi AV, et al. Associations between active travel to work and overweight, hypertension, and diabetes in India: a cross-sectional study. PLoS Med. 2013;10(6): e1001459.

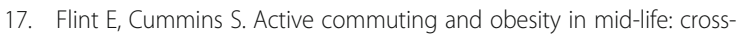
sectional, observational evidence from UK biobank. Lancet Diabetes Endocrinol. 2016:4(5):420-35.

18. Frank LD, Andresen MA, Schmid TL. Obesity relationships with community design, physical activity, and time spent in cars. Am J Prev Med. 2004;27(2): 87-96.

19. Mytton OT, Panter J, Ogilvie D. Longitudinal associations of active commuting with body mass index. Prev Med. 2016;90:1-7.

20. Flint $\mathrm{E}$, Webb $\mathrm{E}$, Cummins $\mathrm{S}$. Change in commute mode and body-mass index: prospective, longitudinal evidence from UK biobank. Lancet Public Health. 2016;1(2):e46-55.

21. Martin A, Panter J, Suhrcke M, Ogilvie D. Impact of changes in mode of travel to work on changes in body mass index: evidence from the British household panel survey. J Epidemiol Community Health. 2015;69(8):753-61.

22. Turrell G, Hewitt BA, Rachele JN, Giles-Corti B, Brown WJ. Prospective trends in body mass index by main transport mode, 2007-2013. J Transp Health. 2018;8:183-92.

23. Dons E, Rojas-Rueda D, Anaya-Boig E, Avila-Palencia I, Brand C, Cole-Hunter T, et al. Transport mode choice and body mass index: cross-sectional and longitudinal evidence from a European-wide study. Environ Int. 2018;119: 109-16. 
24. Sugiyama T, Ding D, Owen N. Commuting by car: weight gain among physically active adults. Am J Prev Med. 2013;44(2):169-73.

25. Grøntved A, Koivula RW, Johansson I, Wennberg P, Ostergaard L, Hallmans $\mathrm{G}$, et al. Bicycling to work and primordial prevention of cardiovascular risk: a cohort study among Swedish men and women. J Am Heart Assoc. 2016; 5(11):e004413.

26. NCD Risk Factor Collaboration (NCD-RisC). Worldwide trends in body-mass index, underweight, overweight, and obesity from 1975 to 2016: a pooled analysis of 2416 population-based measurement studies in 128.9 million children, adolescents, and adults. Lancet. 2017;390(10113):2627-42.

27. Ahima RS, Lazar MA. Physiology. The health risk of obesity--better metrics imperative. Science. 2013;341(6148):856-8

28. Akter $\mathrm{S}$, Nakagawa T, Honda T, Yamamoto S, Kuwahara K, Okazaki $\mathrm{H}$, et al. Smoking, smoking cessation, and risk of mortality in a Japanese working population- Japan epidemiology collaboration on occupational health study. Circ J. 2018;82(12):3005-12.

29. Kuwahara K, Honda T, Nakagawa T, Yamamoto S, Akter S, Hayashi T, et al. Associations of leisure-time, occupational, and commuting physical activity with risk of depressive symptoms among Japanese workers: a cohort study. Int J Behav Nutr Phys Act. 2015;12(1):119.

30. Mytton OT, Ogilvie D, Griffin S, Brage S, Wareham N, Panter J. Associations of active commuting with body fat and visceral adipose tissue: a crosssectional population based study in the UK. Prev Med. 2018;106:86-93.

31. Panter J, Mytton O, Sharp S, Brage S, Cummins S, Laverty AA, et al. Using alternatives to the car and risk of all-cause, cardiovascular and cancer mortality. Heart. 2018;104(21):1749-55.

32. Rissel C, Curac N, Greenaway M, Bauman A. Physical activity associated with public transport use--a review and modelling of potential benefits. Int J Environ Res Public Health. 2012;9(7):2454-78.

33. Yamamoto S, Nakagawa T, Matsushita Y, Kusano S, Hayashi T, Irokawa M, et al. Visceral fat area and markers of insulin resistance in relation to colorectal neoplasia. Diabetes Care. 2010;33(1):184-9.

34. Kuwahara K, Honda T, Nakagawa T, Yamamoto S, Akter S, Hayashi T, et al. Leisure-time exercise, physical activity during work and commuting, and risk of metabolic syndrome. Endocrine. 2016;53:710-21.

35. Patterson R, Webb E, Hone T, Millett C, Laverty AA. Associations of public transportation use with Cardiometabolic health: a systematic review and meta-analysis. Am J Epidemiol. 2019;188(4):785-95.

36. Church T, Martin CK. The obesity epidemic: a consequence of reduced energy expenditure and the uncoupling of energy intake? Obesity. 2018; 26(1):14-6.

37. Kuwahara K, Honda T, Nakagawa T, Yamamoto S, Hayashi T, Mizoue T. Body mass index trajectory patterns and changes in visceral fat and glucose metabolism before the onset of type 2 diabetes. Sci Rep. 2017;7:43521.

38. Kramer CK, Zinman B, Retnakaran R. Are metabolically healthy overweight and obesity benign conditions?: a systematic review and meta-analysis. Ann Intern Med. 2013;159(11):758-69.

39. Swift DL, Johannsen NM, Lavie CJ, Earnest CP, Church TS. The role of exercise and physical activity in weight loss and maintenance. Prog Cardiovasc Dis. 2014;56(4):441-7.

40. Monda KL, Adair LS, Zhai F, Popkin BM. Longitudinal relationships between occupational and domestic physical activity patterns and body weight in China. Eur J Clin Nutr. 2008;62(11):1318-25.

41. Moller NC, Ostergaard L, Gade JR, Nielsen JL, Andersen LB. The effect on cardiorespiratory fitness after an 8-week period of commuter cycling--a randomized controlled study in adults. Prev Med. 2011;53(3):172-7.

42. Quist JS, Rosenkilde M, Petersen MB, Gram AS, Sjodin A, Stallknecht B. Effects of active commuting and leisure-time exercise on fat loss in women and men with overweight and obesity: a randomized controlled trial. Int J Obes. 2018;42(3):469-78.

43. Lerssrimongkol C, Wisetborisut A, Angkurawaranon C, Jiraporncharoen W, Lam KB. Active commuting and cardiovascular risk among health care workers. Occup Med (Lond). 2016;66(6):483-7.

44. Menai M, Charreire H, Feuillet T, Salze P, Weber C, Enaux C, et al. Walking and cycling for commuting, leisure and errands: relations with individual characteristics and leisure-time physical activity in a cross-sectional survey (the ACTI-cites project). Int J Behav Nutr Phys Act. 2015;12:150.

45. Ministry of Land, Infrastructure, Transport and Tourism. White paper on Land, Infrastructure, Transport and Tourism in Japan. Tokyo. 2017:2018.

46. Japan Sports Agency. FUN + WALK PROJECT. http://www.mext.go.jp/sports/ en/b_menu/policy/sportsnation/funwalk.htm (accessed on 14 Oct 2019).
47. Sallis JF, Bull F, Burdett R, Frank LD, Griffiths P, Giles-Corti B, et al. Use of science to guide city planning policy and practice: how to achieve healthy and sustainable future cities. Lancet. 2016;388(10062):2936-47.

48. Japanese Association of Exercise Epidemiology Official Statement Committee. Statement of endorsing "FUN+WALK PROJECT", a new project led by Japan sports agency. Res Exerc Epidemiol. 2018;20(1):49-53.

49. Ohkawara K, Tanaka S, Miyachi M, Ishikawa-Takata K, Tabata I. A doseresponse relation between aerobic exercise and visceral fat reduction: systematic review of clinical trials. Int J Obes. 2007;31(12):1786-97.

50. Williams PT. Greater weight loss from running than walking during a 6.2-yr prospective follow-up. Med Sci Sports Exerc. 2013;45(4):706-13.

51. Chin SH, Kahathuduwa CN, Binks M. Physical activity and obesity: what we know and what we need to know. Obes Rev. 2016;17(12):1226-44.

52. Campbell SDI, Brosnan BJ, Chu AKY, Skeaff CM, Rehrer NJ, Perry TL, et al. Sedentary behavior and body weight and composition in adults: a systematic review and meta-analysis of prospective studies. Sports Med. 2018;48(3):585-95.

53. Patterson R, Webb E, Millett C, Laverty AA. Physical activity accrued as part of public transport use in England. J Public Health (Oxf). 2019;41(2):222-30

54. Dimick JB, Ryan AM. Methods for evaluating changes in health care policy: the difference-in-differences approach. JAMA. 2014;312(22):2401-2.

55. Athey S, Imbens GW. Identification and inference in nonlinear difference-indifferences models. Econometrica. 2004;74(2):431-97.

\section{Publisher's Note}

Springer Nature remains neutral with regard to jurisdictional claims in published maps and institutional affiliations.
Ready to submit your research? Choose BMC and benefit from:

- fast, convenient online submission

- thorough peer review by experienced researchers in your field

- rapid publication on acceptance

- support for research data, including large and complex data types

- gold Open Access which fosters wider collaboration and increased citations

- maximum visibility for your research: over $100 \mathrm{M}$ website views per year

At BMC, research is always in progress.

Learn more biomedcentral.com/submissions 